\title{
Influence of Obesity on the Course of Malignant Neoplastic Disease in Patients After Pulmonary Metastasectomy
}

\author{
ADAM RZECHONEK ${ }^{1}$, PIOTR BŁASIAK ${ }^{1}$, GRZEGORZ PNIEWSKI ${ }^{2}$, PIOTR CIERPIKOWSKI ${ }^{1}$, \\ MONIKA MOŚCIBRODZKA ${ }^{3}$, MACIEJ ORNAT ${ }^{4}$, JĘDRZEJ GRZEGRZÓŁKA ${ }^{4}$ and ANNA BRZECKA ${ }^{5}$ \\ ${ }^{1}$ Department and Clinic of Thoracic Surgery, Wroclaw Medical University, Wroclaw, Poland; \\ ${ }^{2}$ Department of Thoracic Surgery, Lower Silesian Centre for Lung Diseases, Wroclaw, Poland; \\ ${ }^{3}$ Institute of Economic Sciences, Department of Statistics and Operational Research, \\ University of Wroclaw, Wroclaw, Poland; \\ ${ }^{4}$ Department of Histology and Embryology, Wroclaw Medical University, Wroclaw, Poland; \\ ${ }^{5}$ Department and Clinic of Pulmonology and Lung Cancer, Wroclaw Medical University, Wroclaw, Poland
}

\begin{abstract}
Background/Aim: The aim of the study was to determine whether increased body mass index (BMI) in patients operated on for lung metastases influences the course of the disease. Materials and Methods: The retrospective data of 97 patients previously operated on for different malignancies were analyzed. There were 40 obese patients $\left(B M I>30 \mathrm{~kg} / \mathrm{m}^{2}\right.$, mean $\left.33.9 \pm 4.5\right)$ and 57 non-obese patients (BMI $\left.25.8 \pm 2.7 \mathrm{~kg} / \mathrm{m}^{2}, p<0.001\right)$. Disease-free interval (DFI), the overall survival (OS) and survival after pulmonary metastasectomy were analyzed. Results: DFI and OS were longer in obese than in non-obese patients (82.1 \pm 83.5 months vs. $43.0 \pm 44.4, p<0.01$ and $110.7 \pm 81.3$ months vs. $69.9 \pm 52.9 p<0.005$, respectively). Survival after pulmonary metastasectomy was 27.2 \pm 25.6 months and was longer in obese and overweight patients than in normal weight patients $(20.2 \pm 18.4$ months vs. $29.4 \pm 26.5, p<0.05)$. Conclusion: Being obese or overweight is a favorable prognostic factor in patients after surgical resection of lung metastases of different malignancies.
\end{abstract}

With the increasing epidemic of obesity in the world, the incidence of malignancies related to obesity also increases (1). Obesity-related cancers include breast cancer in postmenopausal women, colon cancer, cancer of the lower esophagus, gastric cancer, liver cancer, gall bladder cancer,

This article is freely accessible online.

Correspondence to: Adam Rzechonek, Department of Thoracic Surgery, Wroclaw Medical University, 105 Grabiszynska St., 53-439 Wroclaw, Poland. Tel: +48 698642636, e-mail: adam.rzechonek@gmail.com

Key Words: Obesity paradox, pulmonary metastases, metastasectomy, disease-free interval, overall survival. pancreatic cancer, uterine cancer, ovarian cancer and renal cancer (2). Obesity is also associated with increased risk of metastases, including lung metastases, in some cancers (3).

In the course of some malignancies a paradoxical phenomenon has been observed, indicating that obesity may be an oncogenic factor and - at the same time - may constitute a favorable prognostic factor $(4,5)$. The dual and opposite influence of obesity on the course of the same disease has been called the obesity paradox and has been described in some chronic diseases, including cardiovascular (6) and cerebrovascular diseases (7). These paradoxical effects of obesity may occur also in patients with metastases, including patients with malignancies not related to obesity. In a recent large-scale study of 4,010 cancer patients in good general condition, with distant metastases, median OS was twice as high in obese patients as in normal weight patients (8). However, there are also reports stating that there is no beneficial effect of obesity on metastatic neoplastic disease (9-11).

The problem of the influence of obesity on the course of metastatic malignancies has not yet been unequivocally explained. Especially, there are no studies on the influence of obesity on survival of patients with operable lung metastases. Therefore, this study was undertaken to evaluate the long-term outcome of surgical treatment of obese and non-obese patients who after resection of primary neoplasm had lung metastases removed.

\section{Materials and Methods}

Data from 99 patients who had a resection of lung metastasis from different primary malignancies between 2001 and 2016 were analyzed. The study was retrospective, and the condition for including patients in the study was access to anesthesia documentation containing body weight and height prior to performing pulmonary metastasectomy. Analysis was performed in the groups depending on body mass index (BMI). Underweight was diagnosed when the BMI 
in vivo $32: 197-202(2018)$

Table I. The most common coexisting or previously treated diseases in normal weight, overweight and obese patients, who underwent pulmonary metastasectomy.

\begin{tabular}{|c|c|c|c|c|c|c|}
\hline \multirow[b]{2}{*}{ Cardiovascular diseases } & \multicolumn{2}{|c|}{ Normal weight patients $n=18$} & \multicolumn{2}{|c|}{ Overweight patients $n=39$} & \multicolumn{2}{|c|}{ Obese patients $n=40$} \\
\hline & 4 & $22 \%$ & 15 & $38 \%$ & 21 & $53 \%$ \\
\hline Previously treated other malignancy & 2 & $11 \%$ & 4 & $10 \%$ & 5 & $13 \%$ \\
\hline Diabetes & 2 & $11 \%$ & 5 & $12 \%$ & 9 & $23 \%$ \\
\hline Hypothyroidism & 1 & $6 \%$ & 0 & 0 & 5 & $13 \%$ \\
\hline Respiratory system diseases & 0 & 0 & 4 & $10 \%$ & 2 & $5 \%$ \\
\hline
\end{tabular}

Table II. Type of surgery in the normal weight, overweight and obese patients who underwent pulmonary metastasectomy.

\begin{tabular}{|c|c|c|c|c|c|c|}
\hline \multirow{2}{*}{$\begin{array}{l}\text { Type of surgery } \\
\text { Mechanical resection }\end{array}$} & \multicolumn{2}{|c|}{ Normal weight patients $n=18$} & \multicolumn{2}{|c|}{ Overweight patients $n=39$} & \multicolumn{2}{|c|}{ Obese patients $n=40$} \\
\hline & 12 & $66.7 \%$ & 25 & $64.1 \%$ & 22 & $55.0 \%$ \\
\hline Anatomical resection & 4 & $22.2 \%$ & 13 & $33.3 \%$ & 11 & $27.5 \%$ \\
\hline Non-radical resection & 2 & $11.1 \%$ & 1 & $2.6 \%$ & 6 & $15.0 \%$ \\
\hline Mechanical with partial chest wall resection & 0 & 0 & 0 & 0 & 1 & $2.5 \%$ \\
\hline
\end{tabular}

was below $18.5 \mathrm{~kg} / \mathrm{m}^{2}$ (1 patient), normal body weight when BMI was in the range of $18.5-24.9 \mathrm{~kg} / \mathrm{m}^{2}$ (18 patients), overweight when the BMI was in the range of $25.0-29.9 \mathrm{~kg} / \mathrm{m}^{2}$ (39 patients), obesity class I-IV when BMI was in the range of $30.0-49.9 \mathrm{~kg} / \mathrm{m}^{2}(40$ patients), and obesity class V when BMI was $>50.0 \mathrm{~kg} / \mathrm{m}^{2}$ (1 patient). Two patients with extreme body weight - underweight and obesity class $\mathrm{V}$ - were excluded from the analysis. In the final analysis the material of the study consisted of 97 patients, including 50 women and 47 men, mean age $62.8 \pm 8.7$ years, with a mean BMI of $29.2 \pm 5.3 \mathrm{~kg} / \mathrm{m}^{2}$.

There were 18 normal weight patients (19\%), 39 overweight patients $(40 \%)$ and 40 patients with obesity class I-IV (41\%). Among normal weight patients, there were 9 women and 9 men, aged $61.3 \pm 9.1$ years, with BMI of $22.5 \pm 1.2 \mathrm{~kg} / \mathrm{m}^{2}$. Among the overweight patients there were 18 women and 21 men, aged $61.4 \pm 8$ years, with a BMI of $27.4 \pm 1.1 \mathrm{~kg} / \mathrm{m}^{2}$. Patients with normal weight and overweight were referred to as non-obese patients. The group of obese patients consisted of 23 women and 17 men, aged $64.9 \pm 9$ years, with mean BMI of $33.9 \pm 3.2 \mathrm{~kg} / \mathrm{m}^{2}$. BMI differences between the group of 40 obese patients $(41 \%)$ and the group of 57 normal weight and overweight patients $(59 \%)$ were statistically significant $\left(25.8 \pm 2.7 \mathrm{~kg} / \mathrm{m}^{2} v s .33 .9 \pm 4.5 \mathrm{~kg} / \mathrm{m}^{2}, p<0.001\right)$.

The most common coexisting diseases were cardiovascular diseases (hypertension, coronary heart disease, myocardial infarction, stroke, cardiac arrhythmia), previously treated cancers, diabetes mellitus, hypothyroidism and respiratory diseases such as chronic obstructive pulmonary disease and asthma. The incidence of these diseases according to BMI groups is shown in Table I.

Primary tumors included the following histopathological types: squamous cell carcinoma and adenocarcinoma in 81 patients (18 normal weight, 31 overweight and 33 obese), sarcoma in 11 patients ( 1 normal weight, 5 overweight and 5 obese) and melanoma in 5 patients ( 3 overweight and 2 obese). The primary tumor sites were: large intestine (28 patients), kidney (19 patients), breast ( 9 patients), uterus ( 7 patients), lung ( 7 patients), bladder (3 patients), larynx ( 2 patients) thyroid (2 patients), stomach (1 patient), salivary gland (1 patient), tongue (1 patient), soft palate (1 patient). The location of melanoma was as follows: skin (4 patients) and eye (1 patient). The location of sarcoma was as follows: soft tissue (breast, uterus, small intestine) in 10 patients and bone in 1 patient.

Surgical removal of lung metastases consisted of mechanical resection in 69 patients and of anatomical resection in 28 patients. In 1 patient, mechanical resection was associated with partial resection of the chest wall. In 9 patients, metastatic resection was non-radical, because of multiple small nodules detected during the surgical procedure (Table II).

The following parameters were calculated: the time between primary tumor resection and pulmonary metastasectomy, i.e. disease-free interval (DFI); the time between resection of the primary tumor and death or date of the last information about the patient (for all alive patients in mid-November 2016), i.e. overall survival (OS); and the time between pulmonary metastasectomy and the death or date of last information about the patient. Information about the date of death was obtained from the Regional Office for Civil Status and the Center for Personalization of Documents of the Ministry of Interior and Administration in Warsaw.

In the statistical analysis of the results the program Statistica 12 (Krakow, Poland) was used. The survival time analysis was based on the Kaplan-Meier curves with Wilcoxon's test according to Gehan for group comparison. When comparing normal distribution data, Student's $t$-test was used, and for non-parametric data the Mann-Whitney $U$-test was used. The value of $p<0.05$ was considered statistically significant.

\section{Results}

DFI was 59.2 \pm 6.1 months (median: 39 months) for the entire group and was longer in obese than in non-obese patients: $82.1 \pm 83.5$ vs. $43.0 \pm 44.4, p<0.01$. Figure 1 shows Kaplan-Meier 


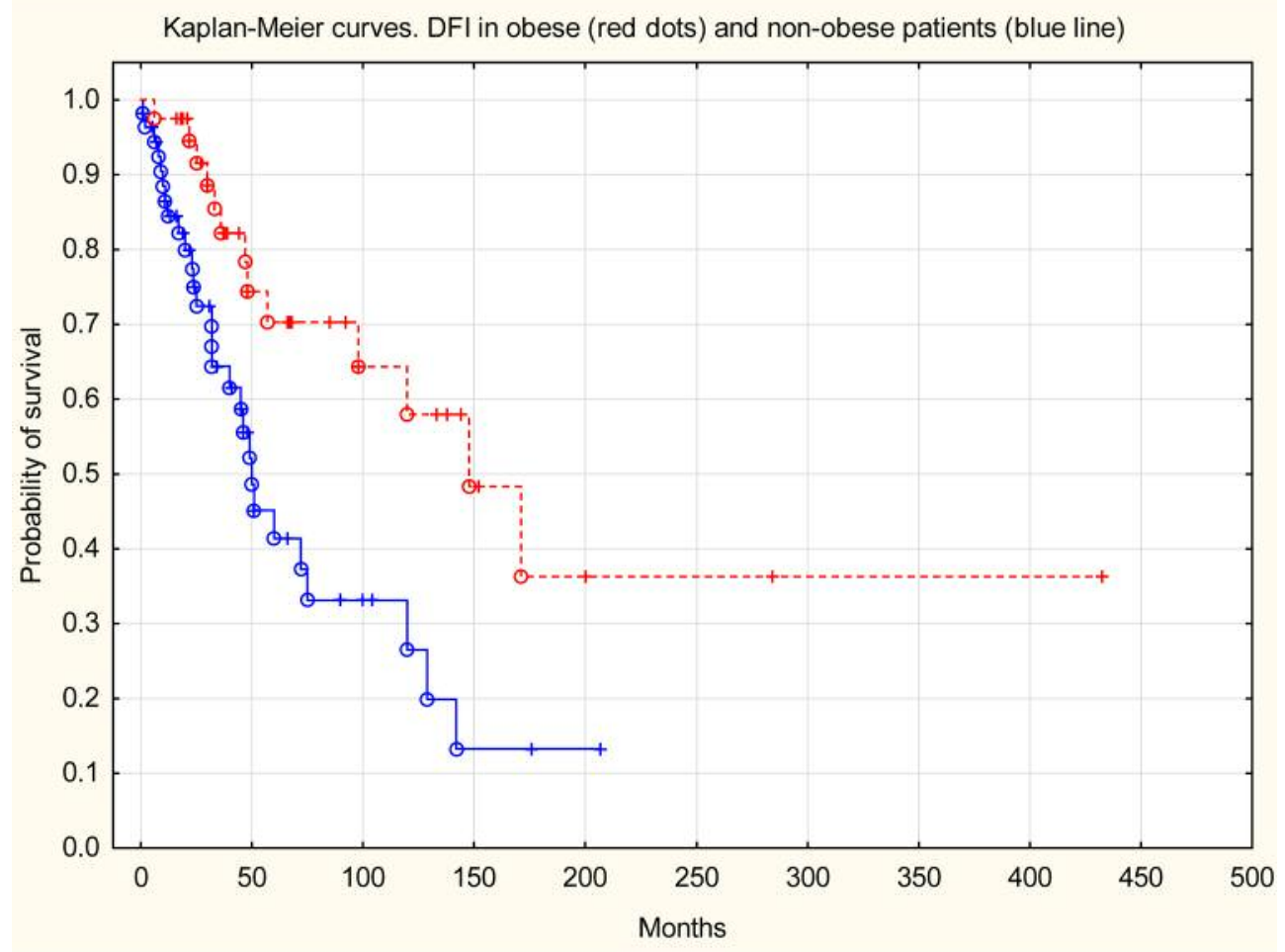

Figure 1. Time between resection of primary neoplasm and resection of pulmonary metastasis in 40 obese and 57 non-obese patients.

curves for DFI in the groups of obese and non-obese patients During the follow-up forty-four patients $(45.4 \%)$ died in 19.1 \pm 15.7 months (median: 33 months) after pulmonary metastasectomy. OS was $86.7 \pm 60.6$ months (median: 65 months) and was longer for obese than non-obese patients: $110.7 \pm 81.3$ months $v s .69 .9 \pm 52.9$ months $p<0.005$. Figure 2 shows Kaplan-Meier curves for OS in the groups of obese and non-obese patients.

The time from pulmonary metastasectomy to death or until the last observation of the patient was 27.2 \pm 25.6 months (median: 23 months). The time from pulmonary metastasectomy to death or until the last observation of the patient in the group of 79 obese and overweight patients was longer than in the group of 18 normal weight patients (20.2 \pm 18.4 months vs. $29.4 \pm 26.5$ months, $p<0.05)$.

\section{Discussion}

In this study, encompassing a group of 97 patients operated on for pulmonary metastases of different histopathological types, including squamous cell carcinoma, adenocarcinoma, melanoma and sarcoma, and of different localization of primary tumors, obesity was found to be a factor indicating longer course of the neoplastic disease - counting both from the surgical removal of the primary tumor to the removal of the lung metastasis and to death or to the last observation. Thus, longer DFI and longer OS in obese as compared with non-obese patients revealed a protective effect of obesity in the course of some neoplastic diseases with pulmonary operable metastases. Moreover, obesity and overweight were found to be favorable prognostic factors, indicating longer survival after pulmonary metastasectomy.

Occurrence of pulmonary metastases is usually a poor prognostic factor, but in selected cases, mainly isolated, peripheral and small $(<3 \mathrm{~cm})$ metastatic lesions in patients with good general condition and without contraindications to surgical treatment, their removal is possible (12). In our material pulmonary metastasectomy was performed in patients with various neoplasms - mostly cancer of the large intestine, kidney, breast, uterus and lung, less often malignancies of other organs. Mean DFI was 59.2 \pm 6.1 months and was almost twice as long in obese as in nonobese patients indicating that obesity was a factor related to slower progression of neoplastic disease after resection of the primary tumor. Mean OS was $86.7 \pm 60.6$ months and similarly as DFI - was longer in obese than in non-obese patients (110.7 \pm 81.3 months vs. 69.9 \pm 52.9 months, $p<0.005)$. Moreover, comparison of survival after pulmonary metastasectomy in the group of obese and overweight patients and in the group of normal weight patients revealed 


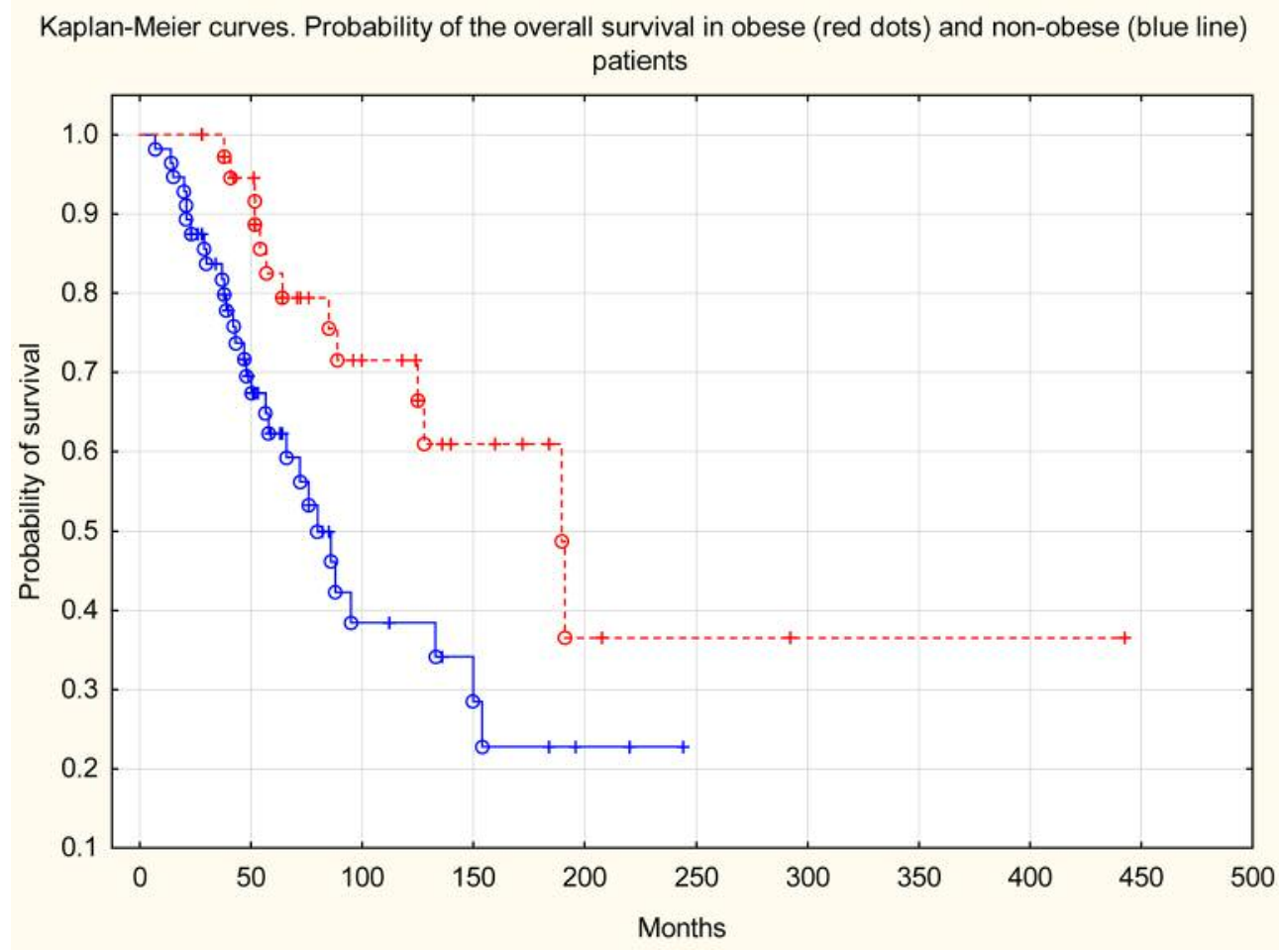

Figure 2. Probability of overall survival in 40 obese and 57 non-obese patients operated on for primary neoplasm and lung metastasis.

approximately 9 -month longer survival in the former group $20.2 \pm 18.4$ months $v s .29 .4 \pm 26.5$ months, $p<0.05$.

More than half of our patients, i.e. $62(64 \%)$, suffered from a neoplasm belonging to the group of cancers related to obesity, such as colorectal, breast, uterine, ovarian, and kidney cancer. Obesity is a factor associated with the risk of occurrence of multiple malignancies $(1,2,13-15)$ and the risk of developing metastases in the course of some malignancies $(3,16)$. However, a favorable influence of overweight and obesity on the course of some neoplastic diseases have been also observed (17-19). Recently, a few studies have reported a relation between obesity and overweight and better prognosis in some cancer patients (2022). In patients with locally advanced non-small-cell lung cancer obesity was associated with increased OS (22). In the early stage of colorectal cancer, the risk of death was lowest in the overweight patients (20). In different histopathological types of cancer, the risk of death decreased with increasing subcutaneous fat tissue (21).

Increased OS in obese patients with metastases has been observed in some other studies $(8,23,24)$. In patients with remote metastases of nasopharyngeal cancer, obesity and overweight were favorable prognostic factors related to increased OS compared to non-obese patients (24). In patients with colorectal cancer who had surgery because of liver metastases (median follow-up of 39 months), obesity was a factor related to longer OS (23). In patients undergoing radiotherapy due to metastases of neoplasms of various organs, lower all-cause mortality was observed in both obese patients and overweight patients compared to patients with normal weight (8). However, we could not find any published data regarding the influence of obesity at the time of pulmonary metastasectomy on DFI and OS.

In considering the relationship between obesity and the course of neoplastic disease, the impact of such obesityrelated factors as adiponectin and impaired glucose metabolism (23) can be taken into account. In patients with non-metastatic kidney cancer a negative correlation between adiponectin and BMI and shorter OS in patients with high serum adiponectin was observed (5). In obese patients surgically treated for liver metastases of colorectal cancer, diabetes had an unfavorable influence on OS, unlike in obese patients without diabetes (23).

The strengths of our study are the large number of patients with operable pulmonary metastases and the long time of observation of the patients. The weak point in our study is that the causes of death of the observed patients were unknown; whether these were cancer-related causes of death or related to cardiovascular or other diseases remains unexplained. The relationship between obesity and survival 
may differ depending on the cause of death: for example, obese patients with renal cancer have been shown to have shortened OS, but after taking into account the causes of death, it turned out that survival related only to cancer was longer in obese than in non-obese patients; the authors called this phenomenon a 'paradox within a paradox' (25). The disadvantage of our work is also that we did not have data on BMI at the time of primary tumor surgery or data on the dynamics of BMI changes in the course of the disease.

\section{Conclusion}

In patients with operable pulmonary metastases of different malignancies, increased BMI significantly influences the course of the neoplastic disease. Overall survival and diseasefree interval are longer in obese than in non-obese patients undergoing pulmonary metastasectomy. Being obese or overweight is a favorable prognostic factor in patients after surgical resection of lung metastases of different malignancies.

\section{Conflicts of Interest}

The Authors declare no conflicts of interest in relation to this article

\section{Acknowledgements}

This study was supported by the statutory budget of Wroclaw Medical University.

\section{References}

1 Andersson TM, Weiderpass E, Engholm G, Lund AQ, Olafsdottir E, Pukkala E, Stenbeck M and Storm H: Avoidable cancer cases in the Nordic countries - The impact of overweight and obesity. Eur J Cancer 79: 106-118, 2017.

2 Freisling H, Arnold M, Soerjomataram I, O'Doherty MG, Ordóñez-Mena JM, Bamia C, Kampman E, Leitzmann M, Romieu I, Kee F, Tsilidis K, Tjønneland A, Trichopoulou A, Boffetta P Benetou V, Bueno-de-Mesquita HBA, Huerta JM, Brenner H, Wilsgaard $\mathrm{T}$ and Jenab M: Comparison of general obesity and measures of body fat distribution in older adults in relation to cancer risk: meta-analysis of individual participant data of seven prospective cohorts in Europe. Br J Cancer 116: 1486-1497, 2017.

3 Osman MA and Hennessy BT: Obesity correlation with metastases development and response to first-line metastatic chemotherapy in breast cancer. Clin Med Insights Oncol 9: 105$112,2015$.

4 Chung IY, Lee JW, Lee JS, Park YR, Min YH, Lee Y, Yoon TI, Sohn G, Lee SB, Kim J, Kim HJ, Ko BS, Son BH and Ahn SH: Interaction between body mass index and hormone-receptor status as a prognostic factor in lymph-node-positive breast cancer. PLoS One 12: e0170311, 2017.

5 Ito R, Narita S, Huang M, Nara T, Numakura K, Takayama K, Tsuruta H, Maeno A, Saito M, Inoue T, Tsuchiya N, Satoh S and Habuchi T: The impact of obesity and adiponectin signaling in patients with renal cell carcinoma: A potential mechanism for the "obesity paradox". PLoS One 12: e0171615, 2017.
6 Lavie CJ, Milani RV and Ventura HO: Obesity and cardiovascular disease: risk factor, paradox, and impact of weight loss. J Am Coll Cardiol 53: 1925-1932, 2009.

7 Brzecka A and Ejma M: Obesity paradox in the course of cerebrovascular diseases. Adv Clin Exp Med 24: 379-383, 2015.

8 Tsang NM, Pai PC, Chuang CC, Chuang WC, Tseng CK, Chang KP, Yen TC, Lin JD and Chang JT: Overweight and obesity predict better overall survival rates in cancer patients with distant metastases. Cancer Med 5: 665-675, 2016.

9 Choi Y, Lee YH, Park SK, Cho H and Ahn KJ: Association between obesity and local control of advanced rectal cancer after combined surgery and radiotherapy. Radiat Oncol J 34: 113-120, 2016.

10 Choi Y, Park SK, Ahn KJ, Cho H, Kim TH, Yoon HK and Lee YH: Being overweight or obese increases the risk of progression in triple-negative breast cancer after surgical resection. J Korean Med Sci 31: 886-891, 2016.

$11 \mathrm{Ye} \mathrm{S}$, Wen $\mathrm{H}$, Jiang $\mathrm{Z}$ and $\mathrm{Wu} \mathrm{X}$ : The effect of visceral obesity on clinicopathological features in patients with endometrial cancer: a retrospective analysis of 200 Chinese patients. BMC Cancer 16: 209, 2016.

12 Mutsaerts EL, Zoetmulder FA, Meijer S, Baas P, Hart AA and Rutgers EJ: Outcome of thoracoscopic pulmonary metastasectomy evaluated by confirmatory thoracotomy. Ann Thorac Surg 72: 230-233, 2001.

13 Drake I, Gullberg B, Sonestedt E, Stocks T, Bjartell A, Wirfält E, Wallström $\mathrm{P}$ and Orho-Melander M: Type 2 diabetes, adiposity and cancer morbidity and mortality risk taking into account competing risk of noncancer deaths in a prospective cohort setting. Int J Cancer 141: 1170-1180, 2017.

14 Kovesdy CP, Furth S and Zoccali C: Obesity and kidney disease: hidden consequences of the epidemic. Rev Med Chil 145: 281$291,2017$.

15 Makarem N, Bandera EV, Lin Y, Jacques PF, Hayes RB and Parekh N: Carbohydrate nutrition and risk of adiposity-related cancers: results from the Framingham Offspring cohort (19912013). Br J Nutr 117: 1603-1614, 2017.

16 Ewertz M, Jensen MB, Gunnarsdóttir KÁ, Højris I, Jakobsen EH, Nielsen D,Stenbygaard LE, Tange UB and Cold S: Effect of obesity on prognosis after early-stage breast cancer. J Clin Oncol 29: 25-31, 2011.

17 Schlesinger S, Siegert S, Koch M, Walter J, Heits N, Hinz S, Jacobs G, Hampe J, Schafmayer C and Nöthlings U: Postdiagnosis body mass index and risk of mortality in colorectal cancer survivors: a prospective study and metaanalysis. Cancer Causes Control 25: 1407-1418, 2014.

18 Shen N, Fu P, Cui B, Bu CY and Bi JW: Associations between body mass index and the risk of mortality from lung cancer: A dose-response PRISMA-compliant meta-analysis of prospective cohort studies. Medicine (Baltimore) 96: e 7721, 2017.

19 Zhang X, Liu Y, Shao H and Zheng X: Obesity Paradox in Lung Cancer Prognosis: Evolving Biological Insights and Clinical Implications. J Thorac Oncol 12: 1478-1488, 2017.

20 Caan BJ, Meyerhardt JA, Kroenke CH, Alexeeff S, Xiao J, Weltzien E, Feliciano EC, Castillo AL, Quesenberry CP, Kwan ML and Prado CM: Explaining the obesity paradox: the association between body composition and colorectal cancer survival (C-SCANS study). Cancer Epidemiol Biomarkers Prev 26: 1008-1015, 2017. 
21 Ebadi M, Martin L, Ghosh S, Field CJ, Lehner R, Baracos VE and Mazurak VC: Subcutaneous adiposity is an independent predictor of mortality in cancer patients. Br J Cancer 117: 148155, 2017.

22 Lam VK, Bentzen SM, Mohindra P, Nichols EM, Bhooshan N, Vyfhuis M, Scilla KA, Feigenberg SJ, Edelman MJ and Feliciano JL: Obesity is associated with long-term improved survival in definitively treated locally advanced non-small cell lung cancer (NSCLC). Lung Cancer 104: 52-57, 2017.

23 Amptoulach S, Gross G and Kalaitzakis E: Differential impact of obesity and diabetes mellitus on survival after liver resection for colorectal cancer metastases. J Surg Res 199: 378-385, 2015.
24 Li W, Shen LJ, Chen T, Sun XQ, Zhang Y, Wu M, Shu WH, Chen C, Pan CC, Xia YF and Wu PH: Overweight/obese status associates with favorable outcome in patients with metastatic nasopharyngeal carcinoma: a 10-year retrospective study. Chin J Cancer 35: 75, 2016.

25 Bagheri M, Speakman JR, Shemirani F and Djafarian K: Renal cell carcinoma survival and body mass index: a dose-response meta-analysis reveals another potential paradox within a paradox. Int J Obes (Lond) 40: 1817-1822, 2016.

Received October 1, 2017

Revised October 18, 2017

Accepted October 24, 2017 